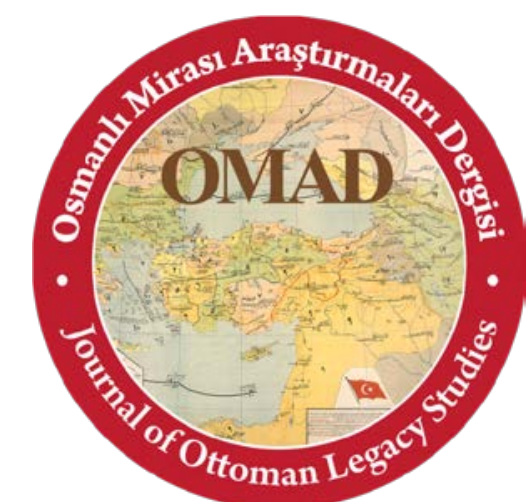

Osmanlı Mirası Araştırmaları Dergisi/Journal of Ottoman Legacy Studies

ISSN 2148-5704

www.osmanlimirasi.net

osmanlimirasi@gmail.com

Cilt 7, Sayı 17, Mart 2020 / Volume 7, Issue 17, March 2020

\title{
İLKNUR (MANGIR) KARAGÖZ (17 NİSAN 1970-15 HAZİRAN 2019)
} İlknur (Mangır) Karagöz (April 17, 1970-June 15, 2019)

\author{
Makale Türü/Article Types : Derleme Makalesi/Review Article \\ Geliş Tarihi/Received Date : 11.03 .2020 \\ Kabul Tarihi/Accepted Date : 23.03.2020 \\ Sayfa/Pages : 1-4 \\ DOI Numaras1/DOI Number : http://dx.doi.org/10.17822/omad.2020.145
}

\section{RIZA KARAGÖZ}

(Prof. Dr.), Ondokuz Mayıs Üniversitesi, Fen-Edebiyat Fakültesi, Tarih Bölümü, Samsun / Türkiye, e-mail: rkaragoz5255@gmail.com, ORCID: https:/ / orcid.org/0000-0002-7268-6190

\section{Atıf/Citation}

Karagöz, Rıza, “İlknur (Mangır) Karagöz (17 Nisan 1970-15 Haziran 2019)”, Osmanlı Mirası Araştırmaları Dergisi, 7/17, 2020, s. 1-4. 



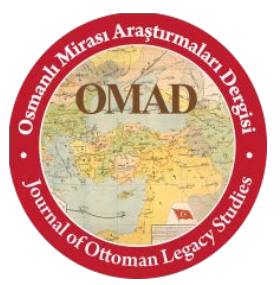

Osmanlı Mirası Araştırmaları Dergisi (OMAD), Cilt 7, Sayı 17, Mart 2020.

Journal of Ottoman Legacy Studies (JOLS), Volume 7, Issue 17, March 2020.

ISSN: 2148-5704

ILLKNUR (MANGIR) KARAGÖZ (17 NISSAN 1970-15 HAZİRAN 2019)

İknur (Mangır) Karagöz (April 17, 1970-June 15, 2019)

\section{Rıza KARAGÖZ}

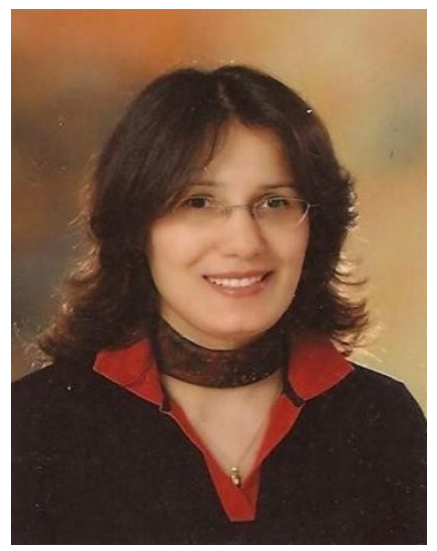

Samsun'un Alaçam ilçesine bağlı Şirinköy (Sakarinek) köyünde doğdu. Annesi Gülfidan, babası Hüseyin Mangır. Ailesinin köydeki lakabı Kanberoğulları'dır.

Okul hayatına 1976 yılında Bafra Gazi Osman Paşa İlkokulu'nda başladı. Orta ve lise öğrenimini de Bafra'da tamamladı. 1984 yilında Atatürk Ortaokulu'nu, 1987 y1lında Bafra Lisesi'ni üstün başarılarla bitirdi.

1987 yllında girdiği Ondokuz Mayıs Üniversitesi (OMÜ) Eğitim Fakültesi Türk Dili ve Edebiyatı Öğretmenliği bölümünden 18 Haziran 1991 tarihinde mezun oldu. Ayn y1 öğretmenlik alan sınavını kazanarak İstanbul Kartal Medine Tayfur Sökmen Lisesi'nde Türk Dili ve Edebiyatı öğretmeni olarak mesleğine başladı. Kısa bir süre sonra Pendik İmam Hatip Lisesi'ne atand (1992).

1992 y1lı sonbaharında girdiği araştırma görevliliği sınavını kazanarak, mezun olduğu bölümde akademik hayata başladı. 1992-1998 yılları arasında OMÜ Eğitim Fakültesi Türk Dili ve Edebiyatı Bölümü'nde, 1998-2006 yılları arasında OMÜ Fen Edebiyat Fakültesi
She was born in Şirinköy (Sakarinek) village of Samsun/Alaçam. Her mother's name is Gülfidan and her father's name is Hüseyin Mangir. Her family's cognomen in the village is Kanberoğulları.

She started school life at Bafra Gazi Osman Paşa Primary School in 1976. She completed secondary and high school education in Bafra. She graduated from Atatürk Secondary School in 1984 and Bafra High School in 1987 with outstanding achievements.

On June 18, 1991, she graduated from Ondokuz Mayıs University (OMU), Faculty of Education, Department of Turkish Language and Literature Teaching, where she started studying in 1987 . She passed the teaching field exam that she took in the same year, and stepped into her working life with her duty of Literature Teaching at İstanbul Kartal Medine Tayfur Sökmen High School. After a short while, she was appointed to Pendik İmam Hatip High School (1992).

In the fall of 1992, she passed the exam for research assistantship and started her academic 
Türk Dili ve Edebiyatı Bölümü'nde Araştırma Görevlisi olarak çalıştı..

1993 y1lında OMÜ Sosyal Bilimler Enstitüsü Türk Dili ve Edebiyatı Anabilim Dalı'nda yüksek lisans eğitimine başladı. Yrd. Doç. Dr. Mehmet Gece danışmanlığında Abay'ın Kara Sözler Adlı Eseri Üzerine Bir Inceleme (Gramer-Metin-Sözlük) adlı teziyle Yeni Türk Dili uzmanı oldu (12 Eylül 1996).

Karagöz, akademik hayatında çok özel yerleri olan iki değerli bilim insanı; Prof. Dr. Leyla Karahan ve Prof. Dr. Mehmet Aydın'ın danışmalıklarında hazırladığı Tarihî Türk Lehçelerinde Slfat ve Zarflarda Pekiştirme ve Derecelendirme adlı teziyle 19 Haziran 2003 tarihinde Yeni Türk Dili bilim doktoru unvanını aldı.

Şubat 2007'de OMÜ Eğitim Fakültesi Türkçe Eğitimi Bölümü'ne Yrd. Doç. Dr. olarak atandi.

3 Mart 2017 tarihinde Marmara Üniversitesi'nde girdiği doçentlik mülakat sınavını geçerek Yeni Türk Dili Doçenti oldu. Doçentlik takdim çalışması, Samsun Göçmen A ğızları I-Bulgaristan Türkleri A Ăızları adıyla yayımlandı. Haziran 2017'de görev yaptığ bölümde Doçentlik kadrosuna atandı.

Türkçe Eğitimi Bölümünde (sonra Türkçe ve Sosyal Bilimler Eğitimi Bölümü Türkçe Öğretmenliği Ana Bilim Dalı) bölüm başkan yardımcılığı (2008-2016) gibi idari görevler de üstlendi.

İlknur (Mangir) Karagöz, Erasmus Koordinatörü (2007- OMÜ Eğitim Fakültesi Türkçe Eğitimi Bölümü), Kalite Kurulu Üyesi (2008-2009 OMÜ Eğitim Fakültesi ), Bölüm Başkan Yardımcısı (2008-2016 OMÜ Eğitim Fakültesi Türkçe Eğitimi ), Yönetim Kurulu Üyesi (2010-2012 Kadın ve Toplum Uygulama ve Araştırma Merkezi), Mevlana Değişim Programı Kurum Koordinatörü (2015 - Ondokuz Mayıs Üniversitesi Eğitim Fakültesi Türkçe Eğitimi Bölümü) ve Senato Üyesi (2018- Ondokuz Mayıs Üniversitesi ) olarak da idari hizmetlerde bulunmuştur.

OMÜ Eğitim Fakültesi'nin Tarih Bölümü'nde araştırma görevlisi olan Rıza Karagöz ile 23 Nisan 1994 tarihinde evlendi. Bu evlilikten Şeyma Ece (1995) ve Işıl Banu (2006) adlı iki kızı oldu.

İlknur Karagöz, 49 yaşındayken, yakalandığı amansız hastalıktan career in the department she graduated from. She worked as a research assistant at OMU Department of Turkish Language and Literature in the Faculty of Education between 1992 and 1998, and at OMU Department of Turkish Language and Literature in the Faculty of Science and Letters between 1998 and 2006.

In 1993, she began her graduate education in OMU, Institute of Social Sciences, Department of Turkish Language and Literature. She received Professor the title of a New Turkish Language expert with her thesis An Overview of Abay's Work titled Black Words" (GrammarText-Vocabulary) under the supervision of Assistant Professor Mehmet Gece (September 12, 1996).

On June 19, 2003, she gained the degree of the Doctor of New Turkish Language with her thesis Intensifying and Grading in Adjectives and Adverbs in Historical Turkish Dialects, which she completed in the same department. Her doctoral thesis was supervised by two valuable scientists, Prof. Dr. Leyla Karahan and Prof. Dr. Mehmet Aydın together, who have great values in her academic life.

In February 2007, she became an academic member by being appointed to OMU, Faculty of Education, Department of Turkish Education as Assistant Professor.

On March 3, 2017, she passed the associate professorship interview at Marmara University and gain the degree of Associate Professor of New Turkish Language. Her Associate Professorship presentation was published under the name of Samsun Immigrant Dialects IBulgarian Turks' Dialects. In June 2017, she was appointed to the position of Assoc. Prof. in the department where she was working.

She also assumed administrative titles such as the co-head of department in OMU Department of Turkish Teaching (then, Division of Turkish Teaching, Department of Turkish and Social Studies Education).

She also fulfilled administrative services such as the Erasmus Coordinator (2007-OMU Faculty of Education Department of Turkish Teaching), Quality Control Member (20082009, OMU Faculty of Education), Vice Chairman (2008-2016-OMU Faculty of Education Department of Turkish Teaching), OMU Women and Community Research Center (OKTAM) membership and Board 
kurtulamayarak 15 Haziran 2019'da fani dünyadan baki âleme irtihal etti. Geride sadece ondan ayrı kalmanın hüznünü her zaman derinden hissedecek bir aile, yetiştirdiği öğrenciler ve sevenlerini değil, aynı zamanda yıllarını vererek yayımladığı ve Türk Dili ve kültürüne önemli katkılar sağlayan araştırmalar bıraktı.

\section{YAYIMLANMIŞ ESERLERİ}

A - Uluslararası Hakemli Dergilerde Makaleler

1 - (2015) "Türkiye Türkçesi Batı Grubu Ağızları İle Drama Göçmenleri Ağızlarında \{idi(n)\} Çekimli Fiilindeki (n) Sesbirimi Üzerine”, Dil Araştırmaları (16), 225-236.

2 - (2012) "The Dialect Of Turkish Immigrants Who Migrated To The Balkans In Bafra And Some Of The Characteristics of Their Dialect”, Journal of Turkish Studies, 74(7), 21392147, 10.7827/TurkishStudies.4150.

3 - (2009) "Edgü Kelimesi Üzerine” Türk Dili Araştırmaları Ylllığ Belleten Dergisi (2006), 127-132.

4 - (2005) "Yahya Kemal in Ses Adlı Şiirinin Özdeşleyim Einfühlung Metoduyla Tahlili”, Türklük Bilimi Araştırmaları (18), 163-177.

B - Uluslararası Bilimsel Toplantılarda Sunulan ve Basılan Bildiri

1 - (2009) "Kutadgu Bilig'in Sözvarlığındaki Bazı Hapax Legomenon Tek Kullanımlıklar", Doğumunun 990. Yllında Yusuf Has Hacib ve Eseri Kutadgu Bilig Bildirileri, 267-273. (Tam Metin Bildiri).

2 - (2008) "Tarihi Türk Lehçelerinde Sifat ve Zarfların Dizim Yoluyla Pekiştirilmesi ve Derecelendirilmesi”, VI. Uluslararası Türk Dili Kurultayl, 3, 2591-2644. (Tam Metin Bildiri).

\section{C - Ulusal Kitaplar}

1 - (2018) Tarihi Türk Lehçelerinde Sifat ve Zarflarda Pekiştirme ve Derecelendirme, Atatürk Kültür Dil ve Tarih Yüksek Kurumu Türk Dil Kurumu, Basım sayısı:1, Sayfa Sayıs1 311, ISBN:978-975-16-3548-8, Türkçe (Bilimsel Kitap)

2 - (2015) Samsun Göçmen Ağızları I Bulgaristan Türkleri A ğızları, E Yazı, Türkçe (Araştırma (Tez Hariç) Kitabı)

D - Ulusal Kitapta Bölüm

1 - (2014) Vezirköprü Araştırmaları,
Membership (2010-2012), Ondokuz May1s University Senate membership (2018-2019).

On April 23, 1994, she married Riza Karagöz, who was a research assistant in the OMU Faculty of Education Department of History. They had two daughters, Şeyma Ece (1995) and Iş1l Banu (2006).

On June 15, 2019, she could not recover from her unrelenting illness, and she departed this life.

\section{PUBLISHED WORKS}

\section{A - Articles in International Refereed}

\section{Journals}

1 - (2015) "Türkiye Türkçesi Batı Grubu Ağızları İle Drama Göçmenleri Ağızlarında \{idi(n)\} Çekimli Fiilindeki (n) Sesbirimi Üzerine”, Dil Araştırmaları (16), 225-236.

2 - (2012) "The Dialect of Turkish Immigrants Who Migrated to The Balkans In Bafra And Some of The Characteristics of Their Dialect”, Journal of Turkish Studies, 74(7), 21392147, Doi: 10.7827/TurkishStudies.4150.

3 - (2009) "Edgü Kelimesi Üzerine” Türk Dili Araştırmaları Yıllı $\breve{l}$ Belleten Dergisi (2006), 127-132.

4 - (2005) "Yahya Kemal in Ses Adlı Şiirinin Özdeşleyim Einfühlung Metoduyla Tahlili”, Türklük Bilimi Araştırmaları (18), 163-177.

B - Papers Presented and Published at the International Scientific Meetings

1 - (2009) "Kutadgu Bilig'in Sözvarlığındaki Bazı Hapax Legomenon Tek Kullanımlıklar", Doğumunun 990. Yllında Yusuf Has Hacib ve Eseri Kutadgu Bilig Bildirileri, 267-273. (Tam Metin Bildiri).

2 - (2008) “Tarihi Türk Lehçelerinde Sıfat ve Zarfların Dizim Yoluyla Pekiștirilmesi ve Derecelendirilmesi”, VI. Uluslararası Türk Dili Kurultayl, 3, 2591-2644. (Tam Metin Bildiri).

\section{C - National Books}

1 - (2018) Tarihi Türk Lehçelerinde Sifat ve Zarflarda Pekiştirme ve Derecelendirme, Atatürk Kültür Dil ve Tarih Yüksek Kurumu Türk Dil Kurumu, Basım sayısı:1, Sayfa Sayıs1 311, ISBN:978-975-16-3548-8, Türkçe (Bilimsel Kitap)

2 - (2015) Samsun Göçmen Ağızları I Bulgaristan Türkleri Ağızlarl, E Yazı, Türkçe [Araştırma (Tez Hariç) Kitabı] 
Bölüm adı: "Vezirköprü Ağzı'nda Kalıplaşmış Dil Birimleri”, Vezirköprü Belediyesi Yay., edt. Cevdet Y1lmaz, s. 527-539, Türkçe (Bilimsel Kitap),

2 - (2014) Çarşamba Araştırmaları, Bölüm adı: "Çarşamba ve Köylerinde Tarla Adları", Çarşamba Bel. Yay., edt. Cevdet Yılmaz, s. 405-418, Türkçe (Bilimsel Kitap).

3 - (2013) Leyla Karahan Armağanı, Bölüm adı: "Bafra'daki Drama Göçmenleri Ağzında Yaşayan Zarf-Fiiller", Akçağ Yay., s. 673-80, Türkçe (Bilimsel Kitap).

4 - (2006) Geçmişten Geleceğe Samsun 1 Kitap, Bölüm adı: "Samsun ve İlçelerinde Yemek Adları", Samsun Büyükşehir Bel. Yay., edt. Cevdet Yılmaz, Türkçe (Bilimsel Kitap).

E - Ulusal Bilimsel Toplantılarda Sunulan ve Yayımlanan Bildiri

1 - (2012) "Bafra ve Köylerine Yerleşen Mübadiller ve Ağızları", V. Ulusal Mübadele ve Balkan Kültürü Araştırmalar Kongresi, (Tam Metin Bildiri).

2 - (2011) "Bafra ve Köylerinde Göçmen Ağzı”, Samsun Sempozyumu, 1, 413-416. (Tam Metin Bildiri).

\section{F - Diğer Yayınlar}

1 - (2005) "Çok Sesli Bir Ölüm de Renk Adlarının Kullanımı Üzerine”, Hece Öykü Dergisi (12), 160-170, (Ulusal Hakemsiz Dergide Özgün Makale)

\section{YÖNETTİĞİ YÜKSEK LİSANS} TEZLERI

1 - Çiçek, Seher, (2012). İlkögrretim 7. Stnıf Öğrencilerinin Anlatısal Metin Yazma Becerilerinde Eşdizimsel Örüntüleme Görünümleri, Ondokuz Mayıs Ü., Eğitim Bilimleri Enstitüsü, Türkçe Eğitimi Ana Bilim Dalı.

2 - Demirci, Nuriye, (2009). 2006 Yll Türkçe Öğretim Programına Göre Hazırlanan 6. ve 7. Sinff Türkçe Ders Kitaplarındaki Dil Yanlışları ve Anlatım Bozuklukları, Ondokuz Mayıs Ü., Sosyal Bilimler Enstitüsü, Türkçe Eğitimi Ana Bilim Dalı.

3 - Çakır, Pınar, (2009). 6.,7., 8. Sinıf Türkçe Ders Kitaplarındaki Öykülerin "Çocuğa Görelikler" Açısından İncelenmesi, Ondokuz Mayıs Ü., Sosyal Bilimler Enstitüsü, Türkçe Eğitimi Ana Bilim Dalı.

\section{D - Chapter in the National Book}

1 - (2014) Vezirköprü Araştırmaları, Bölüm adı: "Vezirköprü Ağzı'nda Kalıplaşmış Dil Birimleri”, Vezirköprü Belediyesi Yay., edt. Cevdet Yılmaz, s. 527-539, Türkçe (Bilimsel Kitap),

2 - (2014) Çarşamba Araştırmaları, Bölüm adı: "Çarşamba ve Köylerinde Tarla Adları", Çarşamba Belediyesi Yay., edt. Cevdet Y1lmaz, s. 405-418, Türkçe (Bilimsel Kitap).

3 - (2013) Leyla Karahan Armağanı, Bölüm adı: "Bafra'daki Drama Göçmenleri Ağzında Yaşayan Zarf-Fiiller", Akçağ Yay., s. 673-80, Türkçe (Bilimsel Kitap).

4 - (2006) Geçmişten Geleceğe Samsun 1 Kitap, Bölüm adı: "Samsun ve İlçelerinde Yemek Adları", Samsun Büyükşehir Bel. Yay., edt. Cevdet Yılmaz, Türkçe (Bilimsel Kitap).

E - Papers Presented and Published at the National Scientific Meetings

1 - (2012) "Bafra ve Köylerine Yerleşen Mübadiller ve Ağızları", V. Ulusal Mübadele ve Balkan Kültürü Araştıșrmaları Kongresi, (Tam Metin Bildiri).

2 - (2011) "Bafra ve Köylerinde Göçmen Ağz1”, Samsun Sempozyumu, 1, 413-416. (Tam Metin Bildiri).

\section{F - Other Publication}

1 - (2005) "Çok Sesli Bir Ölümde Renk Adlarının Kullanımı Üzerine”, Hece Öykü Dergisi (12), 160-170, (Ulusal Hakemsiz Dergide Özgün Makale).

\section{MASTER THESIS SUPERVISED}

1 - Çiçek, Seher, (2012). Ilköğretim 7. Sinıf Ögrrencilerinin Anlatısal Metin Yazma Becerilerinde Eşdizimsel Örüntüleme Görünümleri, Ondokuz Mayıs U., Institute of Educational Sciences-Department of Turkish Education.

2 - Demirci, Nuriye, (2009). 2006 Yll Türkçe Öğretim Programına Göre Hazırlanan 6. ve 7. Sinıf Türkçe Ders Kitaplarındaki Dil Yanlışları ve Anlatım Bozuklukları, Ondokuz Mayis U., Institute of Educational Sciences, Department of Turkish Education.

3 - Çakır, Pınar, (2009). 6.,7., 8. Sınıf Türkçe Ders Kitaplarındaki Öykülerin "Çocuğa Görelikler" Açısından Incelenmesi, Ondokuz Mayıs U., Institute of Educational SciencesDepartment of Turkish Education. 